\title{
Sijem
}

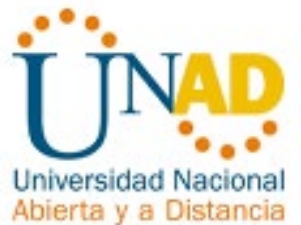

\section{WATER RESOURCES PLANNING IN BIOETHANOL PRODUCTION FROM SUGARCANE}

Danny Ibarra Vega

PhD. Professor.

Universidad Nacional de Colombia Sede Manizales - Colombia

ingdanny09@hotmail.com

Carlos Peña Rincón

PhD. Professor.

Universidad Sergio Arboleda. Bogotá D.C - Colombia

carlos.pena@usergioarboleda.edu.co

Johnny Valencia Calvo

PhD. Professor.

Tecnológico de Antioquia. Medellín - Colombia

johnny.valencia@tdea.edu.co

Johan Manuel Redondo

PhD. Professor.

Universidad Católica de Colombia. Bogota D.C - Colombia

jmredondo@ucatolica.edu.co

Gerard Olivar Tost

PhD. Professor.

Universidad Nacional de Colombia Sede Manizales - Colombia

golivart@unal.edu.co

\section{ABSTRACT}

The biofuels industry has grown and has positioned itself in Colombia for national purposes, these come from biomass sources such as agricultural crops. Bioethanol is the most used in Colombia and is obtained from sugarcane. One of the main concerns of the sector and society, is the high water consumption associated with agricultural crops (9,000 m3 / ha-year), there are currently 232,000 hectares of sugarcane for the production of sugar and bioethanol. Given the aforementioned, the need arises to carry out a 


\section{ㄷำแ}

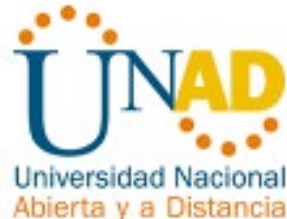

planning of industrial increase of the sector taking into account as a main base the demand and availability of water resources for different activities in the Cauca river basin and the demand for sugarcane crops. In this document it is presented a mathematical model and the evaluation of different scenarios of the estimation of the trend of water consumption in the bioethanol production process in Colombia and in this way to establish scenarios of high risk of water shortage both for the population, interested parties and cane cultivation.

\section{Keywords.}

Bioethanol; System Dynamics; Water Resources.

\section{1) Introduction}

The production of bioethanol in Colombia comes from sugarcane, a crop widely positioned in the country around the Cauca river basin $(232,000 \mathrm{Ha})$. The main impact in the supply chain of this biofuel is associated with the high consumption of water in the production and cultivation of sugar cane $(9,000$ m3 / Ha-year), which can generate supply risks in the face of a possible increase in production (Ibarra, 2017). In this paper a mathematical model of the bioethanol supply chain presented in (Ibarra et al, 2017) was socialized and a proposal was presented to develop a model with a growth limit based on the water consumption indicator.

\section{2) Model for Use and efficiency of water Indicator.}

According to the pilot evaluation of GBEP indicators for Colombia (FAO, 2014), more than $90 \%$ of sugarcane production is positioned in the Cauca River geographical valley, with irrigation activity being one of the most water-related in the production of bioethanol. For the evaluation of this indicator, two activities that generate water consumption (Cultivation and production) are taken into account. In this way, the following causal relationships for this 


\section{SijemL}

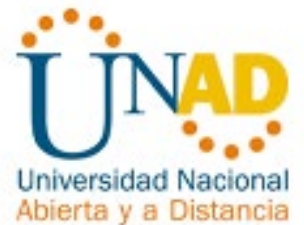

indicator have been considered. Water consumption for cane cultivation increases with the amount of hectares $(\mathrm{Ha})$ of cane planted. Similarly, the second activity that generates a water consumption is evident, which is in the production process, since the harvested cane arrives at a process of enlistment that includes washing and milling by means of mechanical pressure and water, for extraction of the juice that is sent to the bioethanol production process. Therefore, by increasing the quantity of cane to be ready, the consumption of water will also increase. Similarly, increasing the production of Bioethanol will increase the amount of water required in the factory. For this article only the modeling of water consumption by crop is shown.

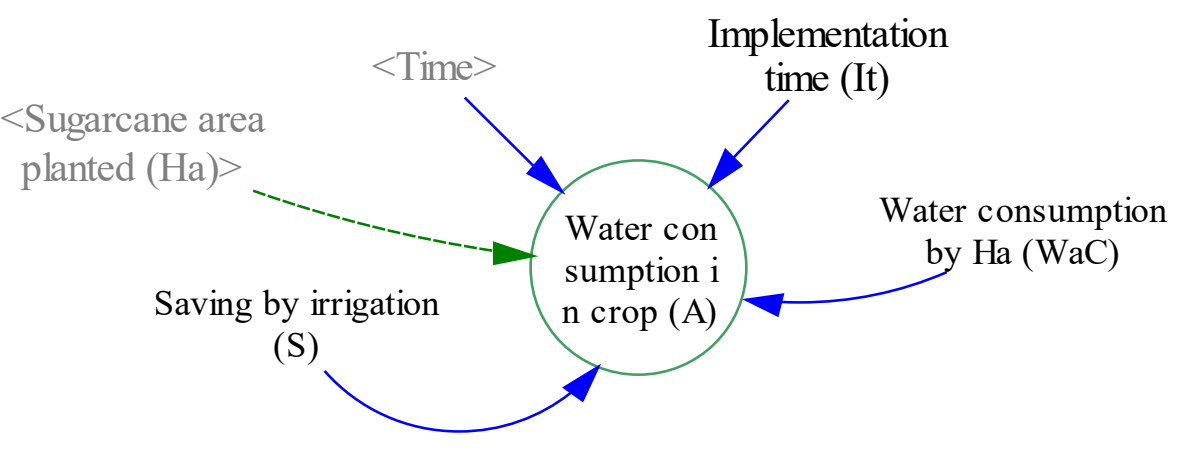

Figure 1. Use and efficiency of water Indicator.

Finally, the diagram that represents the use of water indicator in the production of bioethanol is drawn up, and is linked to the diagram presented in (Ibarra, 2017).

We proceed to formulate the equations to model this indicator. For the representation of total water consumption, the sum of the two main activities identified was taken, which obtained the following equation:

$Y=A$,

where flow A represents the consumption of water in the crop, and a saving parameter $\mathrm{s}$ is associated to it, which would represent savings strategies. The 


\section{Silemt}

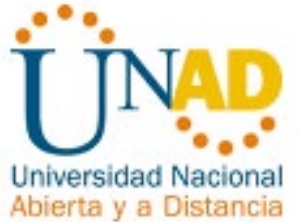

equation is formulated with a piecewise function that shows this decision in a time of implementation It:

$$
A= \begin{cases}(W a C . H a) * S, & \text { si time } \geq I t \\ W a C . H a, & \text { si time }<I t\end{cases}
$$

For the simulation of water consumption, which is mostly focused on the cultivation of sugarcane and the bioethanol production process, the consumption rate of 9,000 m3 of water per hectare of year crop and $0.005 \mathrm{~m} 3$ of water was taken as a basis. per liter of bioethanol produced (CUE, 2012). See figure (2).

In Figure 2. The simulation of the system is shown without any saving strategy and the water consumption behaviors are shown with different saving strategies ( $S=0.2,0.3$ and 0.6 ), starting from the implementation for the year 2017. In the simulation the behavior is observed three irrigation techniques aimed at reducing consumption. Likewise, the restrictions of the defined regions were established based on the estimated use and concession rates for 2010 (Cenicaña, 2010), where they propose an irrational use of values higher than $2 \mathrm{Gm} 3$.

\section{1) Irrigation techniques to reduce water consumption.}

The amount of irrigation water depends on the irrigation technique. In general, open channels are used to irrigate water to crops. The frequency of irrigation is approximately 5 times a year and an annual amount of 5,000 to 9,000 m3 per hectare is applied. However, if irrigation pipe systems are installed, the amount of water can be reduced to 3,600 m3 (Cenicaña, 2010). 

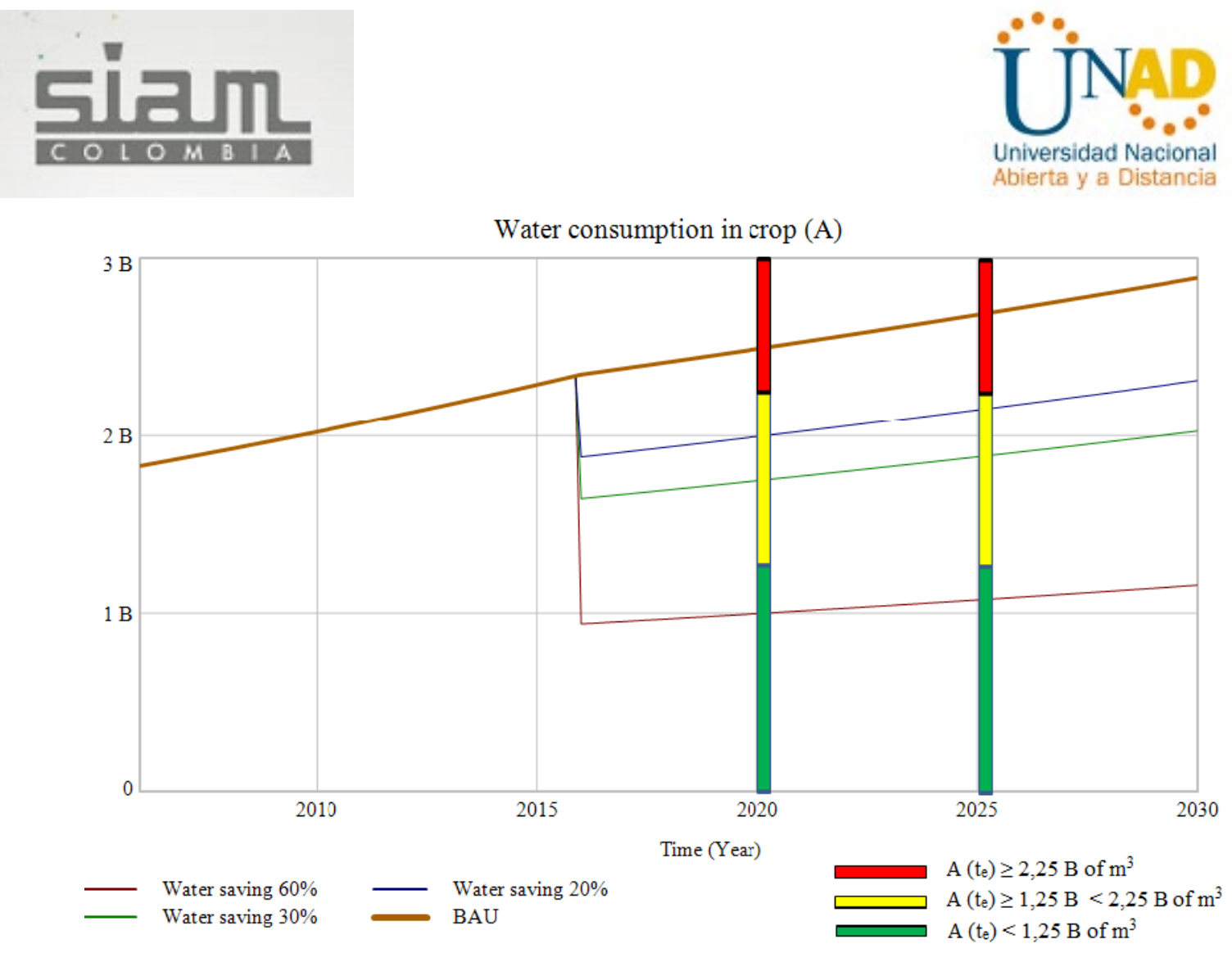

Figura 2. Prospective evaluation of the water consumption indicator.

\section{3) Recommendations to public policy.}

For planning in the bioethanol and other biofuels sector, it is necessary to define clear objectives, both for increased production and sustainability objectives, that is, if production is to be increased, agricultural crops for biofuels and installed production capacity, future scenarios should be measured and modeled to know what would be the impact of natural resources or sustainability indicators, in this case the amount of water available for this. It can be said that, Colombia does not have clear goals regarding the sustainability of the production of bioethanol from sugarcane and it is imperative that a national policy be defined to develop sustainable production schemes. The findings on the water consumption indicator show the need to guide policies with equitable allocation of this resource, that is, that the 


\section{대르는}

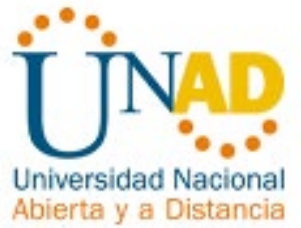

country manages to develop and implement a policy based on prospective consumption scenarios, so as not to generate shortage risks.

\section{REFERENCIAS}

- Cenicaña. (2010). Ahorro de agua y volúmenes aplicados con el uso de tecnologías de riego. Florida, Colombia

- Consorcio CUE, (2012). Capitulo II: Estudio ACV - Impacto Ambiental. In: Consorcio CUE, Evaluación del ciclo de vida de la cadena de producción de biocombustibles en Colombia. Banco Interamericano de Desarrollo, Ministerio de Minas y Energía, Medellín.

- FAO (2014) Pilot testing of GBEP sustainability indicators for bioenergy in Colombia. GBEP. E-ISBN 978-92-5-108568-4 (PDF)

- Ibarra, D. (2017) Modelado para la evaluación de Sostenibilidad en la Cadena de Suministro de Bioetanol. Tesis de Doctorado en IngenieríaAutomática. Departamento de Ingeniería Eléctrica, Electrónica y Computación. Manizales, Colombia.

- Ibarra, D., Redondo, J., Olivar, G. (2017) Tendencias del consumo de agua en la producción de Bioetanol. Revistas ambiente y desarrollo Vol 41, Universidad Javeriana. 